\title{
The Anorectic Girl and Her Father - The Interpersonal and Intrapsychic Meaning to the Girl
}

\author{
Elisabeth Bratt Neuberg ${ }^{1, *}$, Gerhard Andersson ${ }^{1,2}$ \\ ${ }^{1}$ Department of Behavioral Sciences and Learning, Linköping University, Sweden \\ ${ }^{2}$ Department of Clinical Neuroscience, Psychiatry Section, Karolinska Institute, Sweden
}

Copyright $\bigcirc 2017$ by authors, all rights reserved. Authors agree that this article remains permanently open access under the terms of the Creative Commons Attribution License 4.0 International License

\begin{abstract}
Background: Little is known about the role of the fathers of anorectic women. The aim of this study was to investigate the attachment state of mind in anorectic women and their fathers. In addition, two other groups of young women and their fathers were included. Methods: In total there were three groups consisting of women between 18-30 years with anorexia nervosa (AG), drug-dependency problems (DG) and students (SG) without significant problems. We also included the parents of all three groups. The diagnoses of anorexia nervosa and drug-dependency were made according to DSM-IV [1] and ICD-10 [2]. Several methods were used in the study. [3, 4] The Adult Attachment Interview [5] was the focus of this report. Results: The analyses showed that the Anorectic women (AG) had more of a dismissing attachment state of mind, than those who were categorized as enmeshed or secure/autonomous. The attachment of the fathers showed more of a dismissing state of mind than of those categorized as with secure or enmeshed attachment. The subcategories showed that both among the anorectic women and the fathers the dismissing attachment state of mind with restriction of feelings was most represented. The dependent women (DG) had more of an unresolved/enmeshed attachment state of mind than those who were categorized as dismissing or secure/autonomous. The attachment of the fathers showed more of an unresolved/secure attachment state of mind than of those categorized as dismissing or enmeshed. The subcategories showed that enmeshed attachment state of mind of the dependent girls differed from fathers with the unresolved/secure attachment state of mind. Conclusion: This study illustrates the similarities and the differences of attachment styles among anorectic women and their fathers in comparison to the dependent women and their fathers. The insecure attachment is dominant in the two groups but differ in its expressions. The number of participants in the study was low and larger studies are needed to clarify the interpersonal and intra-psychic meaning to the anorectic woman.
\end{abstract}

Keywords Anorectic Women, Fathers, Mothers, between Families, within Families

\section{Introduction}

Anorexia Nervosa (AN) is a complex condition forward by Strober and Johnson [6], and research has been done on diverse topics such as biological correlates, family patterns and on the relation between the anorectic daughter and her mother. In the 90-ties Phares [7, 8], Bornstein [9] drew the attention to the lack of research of the role of the father. There are however some exceptions with Jeammet et al. [10], Engel and Stienen [11] and Eme and Danielek [12] wrote about fathers' relation to their anorectic daughters. Another example is Botta and Dumlao [13], who focused on the underlying patterns of father-child communication. Still there are disproportionately fewer studies examining the role of the father than the mother in psychopathology research, and in particular in the field of eating disorders according to Gale et al. [14]

The number of studies on attachment to important persons, like the father, and its influences on the relation a person with eating disorder have to herself and to others, are increasing. Broberg et al [15] suggested, after summarizing the ongoing research that "attachment is one of few psychological phenomena where the environment plays the crucial role, while the space for genetic influence is limited". Based on clinical observations, a subtype of AN patients has been identified who according to Langenbach and Subic-Wrana [16] is characterized by a consistent idealization of the father who needs the patient for the fulfillment of his own narcissistic needs and secondly, by the patient's need to be idealized by the father, due to suffering in connection with early emotional malnutrition on the part of the mother. Duclos et al. [17] made a comparison of a small group of adolescents with restrictive anorexia and a group without psychiatric disorder and found that both groups had a secure parental representation and attachment style. But in 
comparison with the control group there was a higher proportion of insecure-preoccupied attachment styles in the clinical group for the paternal representation. The highest prevalence of eating disorders (ED) was found among the insecure-dismissing of attachment Salzman [18]. Young women with deactivating strategies were reported elevated levels of ED symptoms according to Cole-Detke and Kobak [19]. In another study on women with eating disorders it was found that one group were characterized by high control/restrictive features, while hyper-activating strategies were associated with the purging/binge eating. This was found when looking at automatic correlates of attachment insecurity in women (Dias et al.) [20].

Spangler commented the study of Steele et al. [21]' and raised the question of paternal relevance for attachment development. Their findings indicate that mother's representation contributes to the adolescent's attachment representation. Spangler pointed to the findings of the longitudinal study by Klaus Grossman and his colleagues, and concluded that mothers and fathers may be influential in different domains, with the father's influence on social outcome of children lying in the domain of experiences during play situations. Doba et al. [22] examined the family functioning in anorexia nervosa and drug dependence disorder. They observed that both patients with anorexia nervosa or drug dependence had a lack of social self-confidence. The family disturbances characterized by low cohesion and emotional reliance on another person were found in both families but suggest that there are differing levels of severity of family disturbances among the family members. Bratt-Neuberg and Andersson [23] showed that the fathers of anorectic daughters did not differ from fathers of dependent daughters or fathers of students and could indicate that anorectic women do not have fathers with elevated psychological distress.
In sum the studies conducted to date show that it is important to include the father of the anorectic daughter in the studies of anorexia nervosa.

The aim of this descriptive study was to investigate the attachment state of mind in anorectic women and fathers with a narrative measurement of attachment (AAI) and compare them with a group of daughters with dependency problem and fathers.

\section{Method}

\subsection{Participants and Procedure}

The three groups investigated were: 1 . The Anorectic Group (AG), 2. The Drug-Dependent Group (DG), and 3. The Student Group (SG). The anorectic and the drug-dependent women were diagnosed according to DSM-IV-TR (APA 2000) ${ }^{1}$ and ICD-10 (WHO 2007) ${ }^{2}$. All the young women and their families were recruited in Stockholm. The AG were recruited from Stockholm Center for Anorexia Center (SCFA), the DG from the Center Therapy and Evaluation of Drugs and Medications, (TUB) and the SG from Adult High School, called ÅSÖ. In total 137 persons participated, with 52 daughters, 43 fathers and 42 mothers. The Adult Attachment Interview took place at the Anorexia Center for the Anorectic groups, at the Dependency Center at Karolinska Hospital for the Drug dependent groups. Some parents were interviewed in their homes if they lived far away from Stockholm. See Table 1.

In total the anorectic group consisted of 14 anorectic girls, 10 fathers, 9 mothers and from the drug-dependent group 8 dependent girls, 9 fathers, 8 mothers.

Table 1. Number and mean age of years of participants

\begin{tabular}{|c|c|c|c|c|c|c|}
\hline & \multicolumn{2}{|c|}{$\begin{array}{c}\text { ANOREXIA } \\
\text { GROUP }\end{array}$} & \multicolumn{2}{c|}{$\begin{array}{c}\text { DRUG-DEPENDENCY } \\
\text { GROUP }\end{array}$} \\
\hline & $\mathrm{N}$ & $\begin{array}{c}\text { Age } \\
(\mathrm{M})(\mathrm{SD})\end{array}$ & $\mathrm{N}$ & $\begin{array}{c}\text { Age } \\
(\mathrm{M})(\mathrm{SD})\end{array}$ & $\mathrm{N}$ & $\begin{array}{c}\text { Age } \\
(\mathrm{M})(\mathrm{SD})\end{array}$ \\
\hline DAUGHTERS & 17 & $24(3.2)$ & 17 & $26(2.5)$ & 18 & $22(3.2)$ \\
\hline FATHERS & 17 & $55(6.0)$ & 13 & $55(6.3)$ & 13 & $52(9.3)$ \\
\hline MOTHERS & 18 & $54(5.2)$ & 11 & $52(6.4)$ & 13 & $51(7.01)$ \\
\hline
\end{tabular}

\subsection{Instrument}

The Adult Attachment Classification System Version 7.2 is a procedure for assessing the state of mind with respect to attachment in adults. It is a clinical semi-structured interview. The focus is on the interviewee's current mental representations of early attachment experiences including the loss of loved ones and other traumatic experiences. The AAI takes usually about an hour to complete and follows a prescribed format in which twenty questions are asked in a set order. The inter-reliability is $80 \%{ }^{5}$.

Explanations of the AAI categories are seen in Table 2. 
Table 2. Explanation of AAI categories

F Secure / Autonomous with respect to attachment: Freely valuing of attachment, while apparently objective

F1 Some setting aside of attachment

F2 Somewhat dismissing or restricting of attachment

F3 Prototypically secure

F4 Some expressed valuing of relationship, accompanied by some manifestations of preoccupation with attachment figures or past trauma

D Dismissing, devaluing or "cut-off" from attachment relationships and experiences

Ds1 Dismissing of attachment

Ds2 Devaluing of attachment

Ds3 Restricted in feeling

Ds4 Cut-off from the source of fear of death of the child

E Preoccupied with or by early attachments or attachment-related experiences

E1 Passive

E2 Angry / conflicted

E3 Fearfully preoccupied by traumatic events

Ud Unresolved Disorganized /Disoriented attachment status

CC Cannot Classify - Contradictory attachment patterns

\section{Results}

\subsection{The Anorectic Group}

Comparison between the anorectic women

The analyses showed that the anorectic women/daughters (14) had more of a dismissing state of mind (8) than those who were categorized as enmeshed (4) or secure/autonomous (2) with respect to attachment.

Comparison between the fathers (AG)

The fathers (10) showed more of a dismissing state of mind (6) than of those categorized as enmeshed (1) secure (3) with respect to attachment.

Comparison between the daughters and their fathers (AG)

The main category found for both the anorectic women/daughters and their fathers pointed to a dismissing state of mind with respect to attachment and the subcategories for both was the restriction of feelings most represented.

See Table 3 and Table 4

Table 3. Anorectic Group Main Category

\begin{tabular}{|c|c|c|c|c|c|}
\hline DAUGHTER & AGE & MAIN CATEGORY & FATHER & AGE & MAIN CATEGORY \\
\hline & 29 & E & & 57 & F \\
\hline & 19 & Ds & & 46 & Ds \\
\hline & 22 & E & & 55 & Ds \\
\hline & 21 & Ds & & 50 & Ds \\
\hline & 27 & E & & 68 & Ds \\
\hline & 22 & Ds & & 51 & U/E \\
\hline & 25 & Ds & & 53 & Ds \\
\hline & 26 & F & & 56 & U/ Ds \\
\hline & 21 & Ds & & 55 & U/F \\
\hline & 24 & F & & 57 & F \\
\hline & 23 & E & & & \\
\hline & 21 & Ds & & & \\
\hline & 31 & Ds & & & \\
\hline
\end{tabular}


Table 4. Anorectic Group Subgroup

\begin{tabular}{|c|c|c|c|c|c|}
\hline DAUGHTER & AGE & SUB CATEGORY & FATHER & AGE & SUB CATEGORY \\
\hline 1. & 29 & E1 & 1. & 57 & F1b \\
\hline 2. & 19 & Ds3 & 2. & 46 & Ds3a \\
\hline 3. & 22 & $\mathrm{E} 2$ & 3. & 55 & Ds1 \\
\hline 4. & 21 & Ds3b & 4. & 50 & Ds3 \\
\hline 5. & 27 & $\mathrm{E} 2$ & 5. & 68 & Ds3b \\
\hline 6. & 22 & Ds3b & 6. & 51 & $\mathbf{U} / \mathbf{E} 1$ \\
\hline 7. & 25 & Ds3a & 7. & 53 & Ds3b \\
\hline 8. & 26 & $\mathrm{~F} 4 \mathrm{~b}$ & 8. & 56 & U/ Ds3b \\
\hline 9. & 21 & Ds3b & 9. & 55 & $\mathrm{U} / \mathrm{F} 2$ \\
\hline 10. & 24 & F 2 & 10. & 57 & $\mathrm{~F} 1 \mathrm{~b}$ \\
\hline 11. & 23 & $\mathrm{E} 2$ & 11. & 48 & \\
\hline 12. & 21 & Ds3b & 12. & & \\
\hline 13. & 31 & Ds3b & 13. & & \\
\hline 14. & 21 & Ds3b & 14. & & \\
\hline
\end{tabular}

\subsection{The Drug-Dependent Group}

Comparison between the dependent women (DG)

The analyses showed that the dependent women/daughters (8) had more of an unresolved/enmeshed state of mind (5) than those who were categorized dismissing (1) and secure/ autonomous (2) with respect to attachment.

Comparison between the fathers (DG)

The attachment for their fathers (9) showed more of an unresolved /secure state of mind (6) than of those categorized as dismissing (2) and enmeshed (1) with respect to attachment.

Comparison between the daughters and their fathers (DG)

The state of mind with respect to attachment differed between the daughters who were more enmeshed and their fathers who were more unresolved/ secure with respect to attachment.

See Table 5 and Table 6

Table 5. Dependent Group Main Category

\begin{tabular}{|c|c|c|c|c|c|}
\hline DAUGHTER & AGE & MAIN CATEGORY & FATHER & AGE & MAIN CATEGORY \\
\hline & 28 & E & & 60 & $\mathbf{U} / \mathbf{F} / \mathbf{E}$ \\
\hline & 26 & $\mathrm{E}$ & & 60 & U/Ds \\
\hline & 26 & $\mathbf{U} / \mathrm{E}$ & & 49 & $F$ \\
\hline & 24 & $\mathbf{U} / \mathbf{E}$ & & 48 & $\mathbf{U} / \mathbb{E}$ \\
\hline & 26 & $\mathbf{U} / \mathbf{F} / \mathbf{E}$ & & 50 & $\mathrm{~F}$ \\
\hline & 28 & $\mathrm{~F}$ & & 59 & $\mathrm{~F}$ \\
\hline & 24 & $\mathbf{U} / \mathbf{E}$ & & 49 & Ds \\
\hline & 23 & Ds & & 55 & $\mathbf{U} / \mathbf{F}$ \\
\hline & & & & 48 & $\mathrm{~F}$ \\
\hline
\end{tabular}


Table 6. Dependent Group Subgroup

\begin{tabular}{|c|c|c|c|c|c|}
\hline DAUGHTER & AGE & $\begin{array}{c}\text { SUB } \\
\text { CATEGORY }\end{array}$ & FATHER & AGE & SUB CATEGORY \\
\hline 1. & 28 & $\mathrm{E} 2$ & 1. & 60 & U/F2/E2 \\
\hline 2. & 26 & $\mathrm{E} 2$ & 2. & 60 & U/Ds3b \\
\hline 3. & 26 & U/E3 & 3. & 49 & F3 \\
\hline 4. & 24 & U/E2 & 4. & 48 & U/E2 \\
\hline 5. & 26 & $\mathrm{U} / \mathrm{F} 4 \mathrm{~b} / \mathrm{E} 3 \mathrm{a}$ & 5. & 50 & F2 \\
\hline 6. & 28 & F2 & 6. & 59 & F2 \\
\hline 7. & 24 & $\mathrm{U} / \mathrm{E} 2$ & 7. & 49 & Ds3 \\
\hline 8. & 23 & Ds1 & 8. & 55 & $\mathrm{U} / \mathrm{F} 4 \mathrm{~b}$ \\
\hline 9. & & & 9. & 48 & F5 \\
\hline
\end{tabular}

Comparisons between the Anorectic Group and Dependent Group

Comparison between the daughters/women (AG, DG)

Both groups were categorized with insecure attachment. The anorectic women had more of a dismissing state of mind (8) in contrast to the dependent women who had more of as enmeshed state of mind (5) with respect to attachment.

Comparison between the fathers (AG, DG)

The fathers in the anorectic group (AG) showed more of a dismissing state of mind (6) with respect to attachment than the fathers in the dependent group (DG) who had more of an unresolved/ secure state of mind (6) with respect to attachment.

\section{Discussion}

The result of this study, assessing the attachment state of mind in women with anorexia nervosa and their fathers and comparing it with the attachment state of mind in young women with drug-dependence and their fathers, showed that both groups shared the insecure attachment state of mind. These findings correspond to several previous studies (see above) and clinical observations. The difference between the two groups lies in the attempt to restrict or limit attention to attachment relationships and/or experiences, which is the response when caregivers have rejecting responses to the signals of their children's attachment needs, found in the anorectic group. Caregivers' inconsistent responses to signals of attachment needs, lead to preoccupation with the attachment relationship, which is the response among the dependent women. In the drug-dependent group the experiences of loss not having been mourned was found among more daughters and fathers than in the anorectic group. In securely attached persons, attachment events had led them to anticipate their caregivers, others availability, understanding and responsiveness. Consequently, they will experience themselves as competent and valuable. The clinical implications would therefore be to develop a secure relationship both for patients whether anorectic or drug-dependent and their fathers in therapy.

\section{Limitations}

The study has several limitations. The sample size was small and consisted of a selected subsample. We only studied the women and their fathers and mothers. It would have been interesting to have data on siblings and grandparents who also may be important for women with AN. In spite of these limitations the observational study has its value as the results gives some indication of state of mind with respect to attachment of the anorectic women and their fathers. These results also point to the similarities and the differences between the two groups and within each group. However larger studies are needed to further investigate the role of the relation of the father and the anorectic daughter.

\section{Conclusions}

The results point to an insecure attachment state of mind in both groups. Among the anorectic women and their fathers it was revealed as limiting awareness and dismissing of attachment relationships and attachment experiences and among the dependent women with a tendency of being overly preoccupied and enmeshed in attachment relationships and attachment experiences. More of an unresolved morning, due to loss of important persons, was found in the dependent group. Further understanding of these attachment orientations could be helpful in therapeutic settings.

\section{REFERENCES}

[1] American Psychiatric Association. (2000). Diagnostic and statistical manual-IV-TR. Arlington, VA. APA.

[2] World Health Organization. (2007). ICD-10 Classification of 
mental and behavioural disorders. 2007 edition. London: Churchill Livingstone

[3] Schalling, D., \& Edman, G. (1987). Personality and vulnerability to psychopathology: The development of the Karolinska Scales of Personality (KSP). Manual in preparation.

[4] Rössel R.J., Weinryb R.M. (1991) Karolinska Psychodynamic Profile (KAPP)

[5] Main M., Goldwin R. E., Hesse E. (2003). Adult Attachment Classification System Version 7.2. Berkeley, CA: University of California.

[6] Strober M., Johnson C. (2012). The Need for Complex Ideas in Anorexia Nervosa: Why Biology, Environment, and Psyche All Matter, Why Therapists Make Mistakes, and Why Clinical Benchmarks Are Needed for Managing Weight Correction. Int J Eat Disord 45:155-178

[7] Phares, V. (1992). Where is Poppa? The relative lack of attention to the role of fathers in child and adolescent psychopathology. American Psychologist, 47,5, 656-664.

[8] Phares, V. (2005). Still looking for Poppa. American Psychologist, 735-736.

[9] Bornstein, R. (1993). Parental representations and psychopathology: A critical review of the empirical literature. J. M. Masling \& Bornstein R.F. (Eds) Psychoanalytic perspectives on psychopathology, Washington D. C. American Psychological Association.

[10] Jeammet, P., Gorge, A., Zweifel, R. Flavigny H. (1973). Le milieu familial des anorexiques mentaux. Incidences sur le traitement. Annales Médicales interne, 124, 3, 247-252.

[11] Engel, K., Stienen, M. (1988). Father types of anorexia nervosa patients: the "bonding", the "brutal", the "weak" and the "absent" father. An empirical study based on a comparison with fathers of a representative normal group. Psychotherapy Psychosomatics, 49, 145-152.

[12] Eme, F. R., Danielak, M.H. (1995). Comparison of fathers and daughters with and without maladaptive eating attitudes. Journal of Emotional and behavioral Disorders. 3, 1, 40-45
[13] Botta, R.A. \& Dumlao, R (2002). How do conflict and communication patterns between fathers and daughter contribute to or offset eating disorder? Health Communication, 14, 199-219.

[14] Gale, C.J., Cluett, E.R., Laver-Bradbury, C. (2013). A review of the father-child relationship in the development and maintenance of adolescent anorexia and bulimia nervosa. Issues Compr Pediatr Nurs., 1-2, 48-69.

[15] Broberg et al (2006) 15 Anknytningsteori: Betydelsen av nära känslomässiga relationer. Natur \& Kultur. P.309

[16] Langenbach, M. and Subic-Wrana, C. (2009) Conscious and unconscious identification of female anorectic patients in in-patient psychotherapy. Psychodynamic practice. Vol.15, No. 2, May 2009, 147-159

[17] Duclos, J.et al. (2014) Pilot Study - Attachment processes in anorexia nervosa: Do adolescents' girls with anorexia nervosa have an insecure attachment? Annales Médico-Psychologiques 172, 714-720

[18] Salzman, J.P. (1996) Primary attachment in female adolescents: association with depression, self-esteem, and maternal identification. Psychiatry 59, 20-33 Cole-Detke and Kobak, R. (1996) Attachment processes in eating disorder and depression. J. Consult. Cling. Psychol. 64, 282-290

[19] Dias, P. et al. (2011) Autonomic correlates of attachment insecurity in a sample of women with eating disorders. Attach. Hum. Dev. 13, 155-167

[20] Spangler Gottfried (2016) Does Mother's Rather than Father's Attachment representation Contribute to the Adolescent's Attachment Representation? Invited Commentary. International Journal of Developmental Science 10 (2016) 121-125

[21] Doba, K. et al. (2014). Is There a Family Profile of Addictive Behaviors? Family Function in Anorexia Nervosa and Drug Dependence Disorder. Journal of Clinical Psychology, Vol. 70 (1), 107-117

[22] Bratt Neuberg, E, Andersson G. (2016) J. Psychological Distress in Anorectic Women, Their Fathers and Mothers. Psychology Research, Vol.6, nr. 5, May 2016 